\title{
Gastric emptying of water in children with severe functional fecal retention
}

\author{
V.P.I. Fernandes ${ }^{1}$, M.C.L. Lima ${ }^{2}$, E.E. Camargo ${ }^{2}$, E.F. Collares ${ }^{1}$, J.M. Bustorff-Silva ${ }^{3}$ and E.A. Lomazi ${ }^{1}$ \\ ${ }^{1}$ Gastroenterologia Pediátrica, Departamento de Pediatria, Universidade Estadual de Campinas, Campinas, SP, Brasil \\ ${ }^{2}$ Medicina Nuclear, Departamento de Radiologia, Universidade Estadual de Campinas, Campinas, SP, Brasil \\ ${ }^{3}$ Cirurgia Pediátrica, Departamento de Cirurgia, Universidade Estadual de Campinas, Campinas, SP, Brasil
}

\begin{abstract}
The objective of this study was to evaluate gastric emptying (GE) in pediatric patients with functional constipation. GE delay has been reported in adults with functional constipation. Gastric emptying studies were performed in 22 children with chronic constipation, fecal retention and fecal incontinence, while presenting fecal retention and after resuming regular bowel movements. Patients (18 boys, median age: 10 years; range: 7.2 to 12.7 years) were evaluated in a tertiary pediatric gastroenterology clinic. Gastric half-emptying time of water (reference range: $12 \pm 3 \mathrm{~min}$ ) was measured using a radionuclide technique immediately after first patient evaluation, when they presented fecal impaction $\left(\mathrm{GE}_{1}\right)$, and when they achieved regular bowel movements $\left(\mathrm{GE}_{2}\right), 12 \pm 5$ weeks after $\mathrm{GE}_{1}$. At study admission, 21 patients had reported dyspeptic symptoms, which were completely relieved after resuming regular bowel movements. Medians (and interquartile ranges) for $\mathrm{GE}_{1}$ and $\mathrm{GE}_{2}$ were not significantly different $[27.0(16)$ and $27.5(21) \mathrm{min}$, respectively $(P=0.10)$ ]. Delayed $G E$ seems to be a common feature among children with chronic constipation and fecal retention. Resuming satisfactory bowel function and improvement in dyspeptic symptoms did not result in normalization of GE data.
\end{abstract}

Key words: Functional constipation; Fecal retention; Soiling; Gastric emptying; Scintigraphy

\section{Introduction}

Fecal retention and nighttime soiling have been strongly correlated with prolonged colonic transit time in children (1). Studies in adults have shown that patients with slow colonic transit constipation usually complain of upper gastrointestinal symptoms, such as nausea, belching, regurgitation, vomiting, abdominal distension, pain, postprandial fullness, and dyspepsia. These symptoms may be explained by the cologastric brake mechanism acting on gastric emptying regulation. Based on this mechanism, rectal fecal retention interferes with gastric emptying by neural reflex (2-4). Despite this observation, some investigators have observed that gastrointestinal symptoms and gastric emptying delay may persist even after partial colectomy (5). Moreover, inappropriate motility of the esophagus (6), small bowel (7) and gallbladder (8) was identified both in adults and children with constipation, mostly of the slow colonic transit subtype $(9,10)$. These observations suggest that other gastrointestinal motility disorders may occur in constipated patients.

Few studies have investigated the relationship between gastric emptying and constipation in children.
Borowitz and Sutphen (11) observed that dyspeptic symptoms improved after treating children with constipation. Hutson et al. (12) did not find any disturbance in gastric emptying of a liquid meal in constipated children, but a recent study with both functionally constipated and dyspeptic children showed prolonged gastric emptying of a solid-liquid meal, which also improved after the treatment of constipation (13).

Based on these apparently contradictory results, the objective of the present study was to evaluate gastric emptying and dyspeptic symptoms in a group of children with severe functional constipation and soiling while presenting fecal retention and after resuming regular bowel movements.

\section{Material and Methods}

Constipated children referred to a tertiary outpatient Gastroenterology Clinic were invited to participate in this study. Inclusion criteria were a diagnosis of functional fecal retention according to Rome III criteria (14) with concomitant fecal impaction and soiling. Fecal retention

Correspondence: V.P.I. Fernandes, , Rua Antonio Lapa, 1032, 13025-242 Campinas, SP, Brasil. Fax: +55-19-3252-2903. E-mail: vpinaba@terra.com.br 
was identified by a characteristic palpable abdominal mass, rectal examination or an abdominal radiograph.

Constipated children who had been referred by general pediatricians from public primary healthy units to our tertiary outpatient clinic from 2000 to 2003 were eligible to participate in the study. At the first visit with a pediatric gastroenterologist, all patients had chronic fecal retention and reported episodes of fecal retentive incontinence since they were severely and chronically constipated. In addition, they reported at least one of the following symptoms: 1) passage of hard and large diameter stools, 2) pain or discomfort during fecal passage, and 3) defecation frequency $<3$ times/week (15). In order to minimize hormonal interference of the menstrual cycle with gastric emptying, only pre-menarche girls were included in the study (16).

A full medical history was obtained and a complete physical examination was performed at first visit for the exclusion of organic causes of constipation such as Hirschsprung's disease, intestinal neuronal disease, spinal or anal anomalies, previous colon surgery, metabolic or renal abnormalities, hypothyroidism, and mental or motor disability. Anal manometry and a barium enema were performed in all patients.

Data on symptoms were obtained at first visit according to validated studies on gastrointestinal symptoms in children $(17,18)$. The following symptoms were investigated: postprandial abdominal pain, anorexia, early satiety, nausea, postprandial abdominal distension, postprandial epigastric pain, and postprandial fullness.

Informed consent for participation in study was obtained from the parents of all patients, and the experimental design of the study was approved by the Independent Ethics Committee of Faculdade de Ciências Médicas, Universidade Estadual de Campinas.

After the first clinical visit, patients were submitted to the first gastric emptying study $\left(G_{1}\right)$, while presenting rectal fecal impaction. Oral laxatives were not prescribed at that time. Gastric half-emptying time $\left(t_{1 / 2}\right)$ was evaluated with a test meal of $300 \mathrm{~mL} / \mathrm{m}^{2}$ water labeled with ${ }^{99 \mathrm{~m}}$ Tc-sulfur colloid (1.0 mCi) (19). After an overnight fast, the patient was asked to drink the test meal and was placed in dorsal position in a scintigraphy camera. The camera was equipped with a low energy and highresolution collimator to achieve dynamic images of the stomach every $60 \mathrm{~s}$, for a minimum time of $30 \mathrm{~min}$. Data analysis was performed using the radionuclide activity versus time curve that identified the gastric $t_{1 / 2}$. The laboratory reference value for gastric $t_{1 / 2}$ studies (12 $\pm 3 \mathrm{~min}$ ) was obtained previously in young healthy adults $(20,21)$.

After $\mathrm{GE}_{1}$, patients were admitted to the hospital for fecal removal procedures. This was achieved using $20 \mathrm{~mL} / \mathrm{kg} \mathrm{12 \%}$ glycerin saline enemas, repeated until complete fecal removal, which was confirmed by an abdominal radiograph. At discharge, patients were pre- scribed osmotic laxatives (magnesium hydroxide or lactulose) at a dose of $1 \mathrm{~mL} / \mathrm{kg}$ once daily. Parents were also instructed to use an enema if no bowel movement occurred for more than 2 days, according to NASPGHAN recommendations (22).

At first visit, patients were classified as severely constipated based on 1) bowel movement frequency ranging from no spontaneous bowel movement (evacuation only under cleansing enemas) to less than 3 times a week, and 2) retentive incontinence confirmed by symptoms and physical examination if a fecal mass was palpable in the abdomen and/or fecal retention was present during a rectal examination. Constipation recovery was defined when patients achieved a bowel frequency of more than 3 times a week and reported soft feces in a spontaneous and painless evacuation, even if they were still on laxative medication. At $\mathrm{GE}_{2}$ time, i.e., when patients had achieved regular bowel movements, 16 patients were using osmotic laxatives at doses ranging from 5 to $15 \mathrm{~mL}$ a day. In order to confirm absence of fecal retention at $\mathrm{GE}_{2}, 1$ day before the nuclear study patients and parents were questioned about fecal incontinence and bowel habits, gastrointestinal symptoms and a physical examination was performed. The gastric emptying study was performed $48 \mathrm{~h}$ after withdrawal of laxative medication.

\section{Statistical analysis}

Sample size estimation was based on an expected $15 \%$ reduction of gastric $t_{1 / 2}$ after normalization of bowel habits in severely constipated patients (4), presuming a $5 \%$ alpha error, a power of $80 \%$ and estimating a $20 \%$ discontinuation rate. On this basis, it was calculated that a sample size of 22 patients would be needed for completion of this study, considering 28 enrollments with a $20 \%$ dropout (PASS 2005, NCSS, USA).

Data are reported as means $\pm S D$ or median (interquartile range) when appropriate. Median and interquartile ranges were used for gastric emptying values since normal distribution could not be assumed; values for these parameters were compared using the Wilcoxon signed rank test. All calculations were done using SPSS version 16.0. A two-tailed $P$ level of 0.05 was considered to be statistically significant.

\section{Results}

Twenty-eight patients were included in the study, and 23 completed the initial and post-recovery scintigraphy tests. Reasons for not doing the second exam were parental or patient refusal $(n=2)$, discontinuation of treatment $(n=1)$ or lack of constipation improvement ( $n$ $=1$ ). One patient was classified as an outlier because his first $t_{1 / 2}$ reached $183 \mathrm{~min}$, and was excluded from statistical analysis. Patients who did not complete the two studies showed no statistically significant differences 
Table 1. Clinical data of 22 constipated patients and scintigraphic $t_{1 / 2}$ gastric emptying values, before impaction removal $\left(\mathrm{GE}_{1}\right)$ and after recovery from constipation $\left(\mathrm{GE}_{2}\right)$.

\begin{tabular}{lc}
\hline Clinical data & Values \\
\hline Total number of patients & 22 \\
Males, $\mathrm{n}(\%)$ & $18(82)$ \\
Age (years) & $10 \pm 2.2$ \\
Duration of constipation (years) & $6.8 \pm 1.6$ \\
Median (interquartile) $\mathrm{t}_{1 / 2} \mathrm{GE}_{1}$ (min) & $27.0(16)$ \\
Median (interquartile) $\mathrm{t}_{1 / 2} \mathrm{GE}_{2}$ (min) & $27.5(21)$ \\
Mean time between $\mathrm{GE}_{1}$ and $\mathrm{GE}_{2}$ studies (weeks) & $12 \pm 5$ \\
\hline
\end{tabular}

in clinical data compared to the remaining 22 patients (data not shown). Table 1 shows the clinical data of the patients at presentation. All patients showed improvement of constipation and underwent the second nuclear study. No patient had fecal impaction at that time, as confirmed by abdominal, rectal or radiological examination. Sixteen patients were using the osmotic laxative medication lactulose, 5 to $15 \mathrm{~mL}$ once a day at $\mathrm{GE}_{2}$, which was discontinued $48 \mathrm{~h}$ before the exam. The most frequent symptom reported was postprandial abdominal pain, with just 1 patient not complaining of dyspeptic symptoms (Table 2). A barium enema showed mega-rectum and sigmoid elongation, with no strictures, and anal manometry showed the presence of a rectoanal inhibitory reflex.

Gastric emptying values are shown in Figure 1. Scintigraphy studies $\left(\mathrm{GE}_{1}\right.$ and $\mathrm{GE}_{2}$ ) were performed 12 \pm 5 weeks apart (Table 1 ). Median (interquartile range) $\mathrm{t}_{1 / 2} \mathrm{GE}_{1}$ was 27.0 (16) min (range: 7 to $125 \mathrm{~min}$ ) and median $\mathrm{t}_{1 / 2} \mathrm{GE}_{2}$ was 27.5 (21) min (range: 10 to $45 \mathrm{~min}$ ), with no significant difference between values $(P=0.10)$. Gastric emptying values of patients with $t_{1 / 2} G_{1}$ above reference values $(n=17)$ were analyzed separately and even so there was no significant difference between first and post-recovery GE studies, with $t_{1 / 2} G_{1}=29$ (20) and $t_{1 / 2} G_{2}=28$ (38) $\min (P=0.07)$. At $G_{2}$, all patients reported complete relief of symptoms.

Gastric emptying values of patients on laxatives at $\mathrm{GE}_{2}(\mathrm{n}=16)$ did not differ from values of 7 patients not

Table 2. Dyspeptic symptoms reported by 21 of the 22 patients studied (1 patient did not report any symptoms).

\begin{tabular}{lc}
\hline Symptoms & Frequency (\%) \\
\hline Postprandial abdominal pain & 50 \\
Anorexia & 36 \\
Early satiety & 36 \\
Nausea & 32 \\
Postprandial abdominal distension & 32 \\
Postprandial epigastric pain & 23 \\
Postprandial fullness & 23 \\
\hline
\end{tabular}

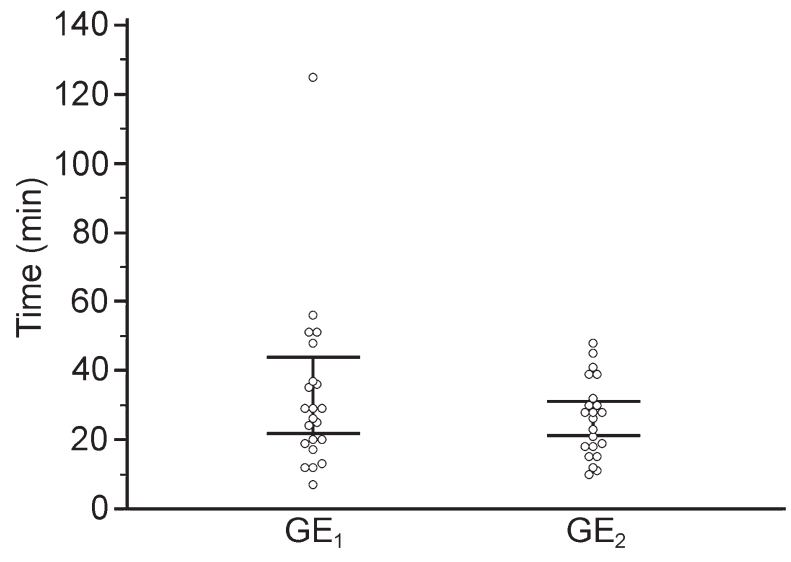

Figure 1. Median gastric $t_{1 / 2}$ emptying values determined by scintigraphic studies. $\mathrm{GE}_{1}$ corresponds to the study done before the removal of fecal impaction and $\mathrm{GE}_{2}$ corresponds to the study done after the patient achieved regular bowel movements. The top horizontal line indicates the $75 \%$ quartile and the bottom line indicates the $25 \%$ quartile. The number of patients in each group was 22. No statistically significant differences were found between the median values $\left(\mathrm{GE}_{1}=27.0 ; \mathrm{GE}_{2}=27.5\right)$ (Wilcoxon signed rank test, $\mathrm{P}=0.10$ ).

using laxatives at such time, with 28 (7) and 27 (8) min, respectively.

\section{Discussion}

The present study shows that pediatric patients with severe chronic constipation had slow gastric $t_{1 / 2}$ before cleansing fecal retention, and that these findings persisted even after recovery from constipation, despite relief in reported dyspeptic symptoms.

Defecation frequency, a criterion for defining intestinal constipation, results from a number of endogenous and exogenous factors. Gastrointestinal motility modulators are considered to be endogenous factors, while exogenous factors are those related to dietary practices and psychological and behavioral aspects. Many events may predispose to determine or just worsen intestinal constipation. The impact of each factor is not clear in most patients. Children whose symptoms are included in the definition of constipation may present a wide variation in clinical manifestations and compose a heterogeneous clinical group that may involve different pathogenic subgroups. Different determining factors may be associated with different outcomes or disease severity and may elicit the development of various mechanisms of gastrointestinal adaptation. In the present study, we evaluated a group of children with similar ages and clinical presentation. Despite the fact that patients presented consistently long-standing disease with fecal retention and at least one episode of fecal incontinence per week, we found a wide range of gastric emptying 
times. While most patients presented slow gastric emptying, values in the reference range were also observed, as well as some clear outliers. This picture may indicate a diversity of pathophysiologic mechanisms or may be the result of adaptative resources to the chronic constipation and fecal retention.

In our study, 2/22 children who performed gastric emptying studies while having fecal impaction showed gastric emptying delay, which improved after treatment. These initial data could be related to the fact that acute rectal distension delays gastric emptying, a mechanism that has been referred to as "cologastric brake" $(4,23)$. On the other hand, in some patients (4/22), despite chronic rectal distension, pre-treatment gastric emptying values were in the normal range. It is possible that in these children the long-standing impaction may have resulted in desensitization of the mechanisms by which rectal distension interferes with gastric emptying. However, of the 22 patients who performed the test without fecal impaction, 16 continued to have delayed gastric emptying. These data might suggest that in these patients gastric emptying delay was not related to the "cologastric brake" effect. Finally, in those patients who showed slow gastric emptying in both studies, a more generalized motility disease could be present and be responsible for both the constipation and the delay in gastric emptying $(9,10)$. Studies in children and adults have suggested that constipation is part of a generalized gastrointestinal (GI) motor disorder in which proximal GI motility can also be impaired $(6,7,9,10)$.

There are conflicting data about an exact relationship between constipation and upper GI symptoms. This controversy may be due to the fact that delayed GE confirms gastric dysmotility but does not prove that symptoms are due to gastroparesis $(24,25)$. The evaluation of factors other than a global delay in GE such as impaired fundic accommodation, antral distension, antral hypomotility, gastric dysrhythmias, visceral hypersensitivity, or psychological disturbances explain, at least in part, the symptoms reported by patients with gastroparesis still in progress (26). A significant correlation was shown between the reduction of postprandial fundus relaxation and the presence of daily upper-Gl symptoms in slowtransit constipated patients (27). It was recently reported that children complaining of upper-GI symptoms such as nausea, vomiting, abdominal pain, and early satiety suffered from chronic unrecognized constipation. The authors observed a significant improvement of symptoms once constipation was treated (11). In our study, all patients reported relief of gastric symptoms after constipation recovery, even though gastric emptying values were not in the reference range.

Although scintigraphy is the gold standard technique for GE evaluation, there are no published reference values for children. Different papers report the use of different meals, markers, volumes, and child ages, which interfere with the interpretation and comparison of the results. In addition, another limitation is the fact that most studies were done in children with gastroesophageal reflux and/or slow gastric emptying transit $(28,29)$. Other techniques such as gastric impedance $(30),\left[{ }^{13} \mathrm{C}\right]$ acetate breath test $(31,32)$ and gastric ultrasonography (13) may be less harmful, but have also not been validated for children and lack reference values. Studies in healthy children are very restricted for ethical reasons and children cannot volunteer for reference standardization.

Considering such limitations, we decided to use liquid meals for gastric emptying evaluation, which is the most straightforward and rapid study to perform, because emptying begins very soon after meal ingestion and the time of half-emptying is easily calculated (21). According to Ziessman et al. (21), studies involving only liquid must be acquired rapidly (1-min frames $x 30 \mathrm{~min}$ ) because normal water and saline emptying is very fast with gastric $t_{1 / 2}$ of 10 to $20 \mathrm{~min}$. In our laboratory, we used the reference value of $12 \pm 3 \mathrm{~min}$ as done by these investigators, which we found to reproduce best the variables used for our tests (21). Previous studies have indicated that approximately $40 \%$ of nuclear medicine laboratories did not validate the normal range for their standard meals, and that the variability of the data is wide, with $20 \%$ using 2 SD (standard deviation) as the normal range, $26 \%$ using 1 SD and $6 \%$ using 1.5 SD (33).

In addition, since gastric emptying rates have a wide interpersonal variation $(34,35)$, the evaluation of a single person in two different situations seemed to be a reasonable variable for investigating the effect of fecal retention in constipated individuals.

We should also point out that liquid meals are considered less useful than solid meals as gastric emptying is generally normal even in conditions such as gastroparesis for solid meals (36). Although a standard solid meal is more frequently used in multicenter protocols for clinical studies (33), our choice of a water meal was based on the faster acquisition of data using liquid meals. In addition, this meal would exert less influence on gastric activity by duodenal feedback. Sodium chloride (120 mM) was considered the meal that exerted a lower stimulus of the osmotic receptors of the duodenum, which are responsible for slowing gastric emptying after a meal (37).

The standard liquid meal used in our laboratory for GE evaluation is water, and since water has a composition more similar to a saline solution (and consequently exerts less effect on osmotic receptors in the duodenum), we decided to use it as the test meal. For the reference volume we used a standardized volume of $300 \mathrm{~mL} / \mathrm{m}^{2}$ as previously published (19). Nevertheless, Hunt and Stubbs (38) demonstrated that the energetic density in a meal of the same consistency is the factor that interferes with gastric emptying, independently of the volume administered.

We treated patients with the goal of restoring bowel movement frequency to at least 3 times a week, with soft 
feces and painless evacuation. In order to minimize the interference of uncontrolled variables, such as adherence to medication, other medical events and discontinuation of treatment, we decided to wait a mean time of 12 weeks before performing the second nuclear study, even though a patient might be taking a minimal dosage of laxative (less than $15 \mathrm{~mL}$ ). According to our experience, during that phase of therapy, severely constipated children were unable to maintain bowel movements without a medication stimulus. Even though there are no literature data proving interference of lactulose with gastric emptying, we decided to withdraw laxative medication $48 \mathrm{~h}$ before the $\mathrm{GE}_{2}$ study as recommended by the American and European Neurogastroenterology and Motility Societies for gastrointestinal motility studies $(24,33)$.

Finally, our study suggests that in those patients who showed slow gastric emptying in both studies, a more

\section{References}

1. Benninga MA, Buller HA, Tytgat GN, Akkermans LM, Bossuyt PM, Taminiau JA. Colonic transit time in constipated children: does pediatric slow-transit constipation exist? J Pediatr Gastroenterol Nutr 1996; 23: 241-251, doi: 10.1097/00005176-199610000-00007.

2. Nightingale JM, Kamm MA, van der Sijp Jr, Morris GP, Walker ER, Mather SJ, et al. Disturbed gastric emptying in the short bowel syndrome. Evidence for a 'colonic brake'. Gut 1993; 34: 1171-1176, doi: 10.1136/gut.34.9.1171.

3. Tjeerdsma HC, Smout AJ, Akkermans LM. Voluntary suppression of defecation delays gastric emptying. Dig Dis Sci 1993; 38: 832-836, doi: 10.1007/BF01295908.

4. Coremans G, Geypens B, Vos R, Tack J, Margaritis V, Ghoos $\mathrm{Y}$, et al. Influence of continuous isobaric rectal distension on gastric emptying and small bowel transit in young healthy women. Neurogastroenterol Motil 2004; 16: 107-111, doi: 10.1046/j.1365-2982.2003.00463.x.

5. Mollen RM, Hopman WP, Oyen WJ, Kuijpers HH, Edelbroek MA, Jansen JB. Effect of subtotal colectomy on gastric emptying of a solid meal in slow-transit constipation. Dis Colon Rectum 2001; 44: 1189-1195, doi: 10.1007/ BF02234643.

6. Mollen RM, Hopman WP, Kuijpers HH, Jansen JB. Abnormalities of upper gut motility in patients with slowtransit constipation. Eur J Gastroenterol Hepatol 1999; 11: 701-708, doi: 10.1097/00042737-199907000-00003.

7. van der Sijp Jr, Kamm MA, Nightingale JM, Britton KE, Granowska M, Mather SJ, et al. Disturbed gastric and small bowel transit in severe idiopathic constipation. Dig Dis Sci 1993; 38: 837-844, doi: 10.1007/BF01295909.

8. Altomare DF, Portincasa P, Rinaldi M, Di Ciaula A, Martinelli $\mathrm{E}$, Amoruso $\mathrm{A}$, et al. Slow-transit constipation: solitary symptom of a systemic gastrointestinal disease. Dis Colon Rectum 1999; 42: 231-240, doi: 10.1007/BF02237134.

9. Soares AC, Lederman HM, Fagundes-Neto $U$, de Morais MB. Breath hydrogen test after a bean meal demonstrates delayed oro-cecal transit time in children with chronic constipation. J Pediatr Gastroenterol Nutr 2005; 41: 221224, doi: 10.1097/01.mpg.0000167499.40074.d7. generalized motility disease could be present and be responsible for both the constipation and the delay in gastric emptying. Recently, Hutson et al. (39) have characterized slow transit constipation in children by using nuclear colonic transit studies. According to these studies, refractory constipation in children may be due to a holdup at the level of the anorectum (functional fecal retention) or the entire colon (slow-transit constipation) (40). More studies including colonic motility exams are necessary to determine the etiology of constipation, to improve treatment alternatives and to define the role of gastric emptying as a prognostic marker in chronic constipation.

\section{Acknowledgments}

\section{Research supported by FAPESP.}

10. Veras Neto MC, Yamada RM, da Costa Pinto EA Gallbladder motility in children with chronic constipation. J Pediatr Gastroenterol Nutr 2008; 46: 414-418, doi: 10.1097/ MPG.0b013e31813347c4.

11. Borowitz SM, Sutphen JL. Recurrent vomiting and persistent gastroesophageal reflux caused by unrecognized constipation. Clin Pediatr 2004; 43: 461-466, doi: 10.1177/ 000992280404300507.

12. Hutson JM, Catto-Smith T, Gibb S, Chase J, Shin YM, Stanton M, et al. Chronic constipation: no longer stuck! Characterization of colonic dysmotility as a new disorder in children. J Pediatr Surg 2004; 39: 795-799, doi: 10.1016/ j.jpedsurg.2004.02.003.

13. Boccia G, Buonavolonta R, Coccorullo P, Manguso F, Fuiano L, Staiano A. Dyspeptic symptoms in children: the result of a constipation-induced cologastric brake? Clin Gastroenterol Hepatol 2008; 6: 556-560, doi: 10.1016/ j.cgh.2008.01.001.

14. Rasquin A, Di Lorenzo C, Forbes D, Guiraldes E, Hyams JS, Staiano A, et al. Childhood functional gastrointestinal disorders: child/adolescent. Gastroenterology 2006; 130: 1527-1537, doi: 10.1053/j.gastro.2005.08.063.

15. Hyams J, Colletti R, Faure C, Gabriel-Martinez E, Maffei $\mathrm{HV}$, Morais MB, et al. Functional gastrointestinal disorders: Working Group Report of the First World Congress of Pediatric Gastroenterology, Hepatology, and Nutrition. J Pediatr Gastroenterol Nutr 2002; 35 (Suppl 2): S110-S117, doi: 10.1097/00005176-200208002-00008.

16. Gill RC, Murphy PD, Hooper HR, Bowes KL, Kingma YJ. Effect of the menstrual cycle on gastric emptying. Digestion 1987; 36: 168-174, doi: 10.1159/000199414.

17. Caplan A, Walker L, Rasquin A. Validation of the pediatric Rome II criteria for functional gastrointestinal disorders using the questionnaire on pediatric gastrointestinal symptoms. J Pediatr Gastroenterol Nutr 2005; 41: 305-316, doi: 10.1097/01.mpg.0000172749.71726.13.

18. Caplan A, Walker L, Rasquin A. Development and preliminary validation of the questionnaire on pediatric gastrointestinal symptoms to assess functional gastrointestinal disorders in 
children and adolescents. J Pediatr Gastroenterol Nutr 2005; 41: 296-304, doi: 10.1097/01.mpg.0000172748.64103.33.

19. Jolley SG, Leonard JC, Tunell WP. Gastric emptying in children with gastroesophageal reflux. I. An estimate of effective gastric emptying. J Pediatr Surg 1987; 22: 923926, doi: 10.1016/S0022-3468(87)80590-0.

20. Collins PJ, Horowitz M, Cook DJ, Harding PE, Shearman DJ. Gastric emptying in normal subjects - a reproducible technique using a single scintillation camera and computer system. Gut 1983; 24: 1117-1125, doi: 10.1136/gut.24.12.1117.

21. Ziessman HA, Chander A, Clarke JO, Ramos A, Wahl RL. The added diagnostic value of liquid gastric emptying compared with solid emptying alone. J Nucl Med 2009; 50: 726-731, doi: 10.2967/jnumed.108.059790.

22. Evaluation and treatment of constipation in infants and children: recommendations of the North American Society for Pediatric Gastroenterology, Hepatology and Nutrition. J Pediatr Gastroenterol Nutr 2006; 43: e1-13, doi: 10.1097/ 01.mpg.0000233159.97667.c3.

23. Youle MS, Read NW. Effect of painless rectal distension on gastrointestinal transit of solid meal. Dig Dis Sci 1984; 29: 902-906, doi: 10.1007/BF01312478.

24. Rao SS, Camilleri M, Hasler WL, Maurer AH, Parkman HP, Saad R, et al. Evaluation of gastrointestinal transit in clinical practice: position paper of the American and European Neurogastroenterology and Motility Societies. Neurogastroenterol Motil 2011; 23: 8-23, doi: 10.1111/ j.1365-2982.2010.01612.x.

25. Patterson D, Abell T, Rothstein R, Koch K, Barnett J. A double-blind multicenter comparison of domperidone and metoclopramide in the treatment of diabetic patients with symptoms of gastroparesis. Am J Gastroenterol 1999; 94: 1230-1234.

26. Maurer $\mathrm{AH}$, Parkman HP. Update on gastrointestinal scintigraphy. Semin Nucl Med 2006; 36: 110-118, doi: 10.1053/j.semnuclmed.2005.12.003.

27. Penning C, Vu MK, Delemarre JB, Masclee AA. Proximal gastric motor and sensory function in slow transit constipation. Scand J Gastroenterol 2001; 36: 1267-1273, doi: 10.1080/00365520150218039.

28. Seibert JJ, Byrne WJ, Euler AR. Gastric emptying in children: unusual patterns detected by scintigraphy. AJR Am J Roentgenol 1983; 141: 49-51.

29. Rosen PR, Treves S. The relationship of gastroesophageal reflux and gastric emptying in infants and children: concise communication. J Nucl Med 1984; 25: 571-574.

30. Smith HL, Hollins GW, Booth IW. Epigastric impedance recording for measuring gastric emptying in children: how useful is it? J Pediatr Gastroenterol Nutr 1993; 17: 201-206, doi: 10.1097/00005176-199308000-00013.

31. Gatti C, di Abriola FF, Dall'Oglio L, Villa M, Franchini F, Amarri $\mathrm{S}$. Is the ${ }^{13} \mathrm{C}$-acetate breath test a valid procedure to analyse gastric emptying in children? J Pediatr Surg 2000; 35: 62-65, doi: 10.1016/S0022-3468(00)80015-9.

32. Braden B, Peterknecht A, Piepho T, Schneider A, Caspary WF, Hamscho $\mathrm{N}$, et al. Measuring gastric emptying of semisolids in children using the ${ }^{13} \mathrm{C}$-acetate breath test: a validation study. Dig Liver Dis 2004; 36: 260-264, doi: 10.1016/j.dld.2003.12.011.

33. Abell TL, Camilleri M, Donohoe K, Hasler WL, Lin HC, Maurer $\mathrm{AH}$, et al. Consensus recommendations for gastric emptying scintigraphy: a joint report of the American Neurogastroenterology and Motility Society and the Society of Nuclear Medicine. J Nucl Med Technol 2008; 36: 44-54, doi: 10.2967/jnmt.107.048116.

34. Troncon LE, Aprile LR, Oliveira RB, lazigi N. Abnormally rapid gastric emptying of an isosmotic liquid meal in patients with megaduodenum. Dig Dis Sci 2000; 45: 2145-2150, doi: 10.1023/A:1026684418333.

35. Troncon LE, Rosa-e-Silva L, Oliveira RB, lazigi N, Gallo L $\mathrm{Jr}$, Foss MC. Abnormal intragastric distribution of a liquid nutrient meal in patients with diabetes mellitus. Dig Dis Sci 1998; 43: 1421-1429, doi: 10.1023/A:1018834025351.

36. Chaudhuri TK, Fink S. Gastric emptying in human disease states. Am J Gastroenterol 1991; 86: 533-538.

37. Hunt JN. Mechanisms and disorders of gastric emptying. Annu Rev Med 1983; 34: 219-229, doi: 10.1146/annurev.me.34.020183.001251.

38. Hunt JN, Stubbs DF. The volume and energy content of meals as determinants of gastric emptying. J Physiol 1975; 245: 209-225.

39. Hutson JM, Chase JW, Clarke MC, King SK, Sutcliffe J, Gibb S, et al. Slow-transit constipation in children: our experience. Pediatr Surg Int 2009; 25: 403-406, doi: 10.1007/s00383-009-2363-5.

40. King SK, Sutcliffe JR, Southwell BR, Chait PG, Hutson JM. The antegrade continence enema successfully treats idiopathic slow-transit constipation. J Pediatr Surg 2005; 40: 1935-1940, doi: 10.1016/j.jpedsurg.2005.08.011. 